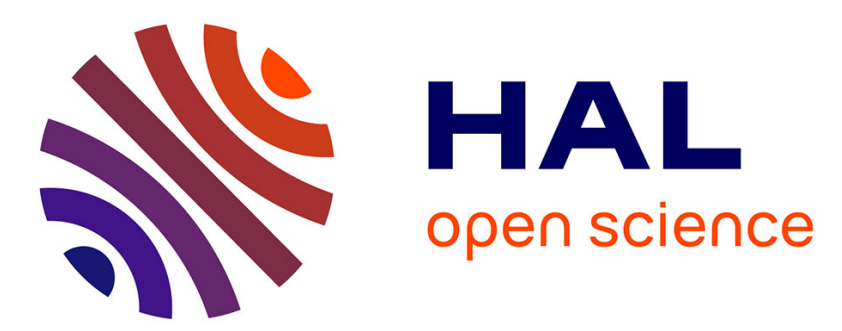

\title{
The nature of the $\mathrm{Pt}(111) / \alpha$-Fe $2 \mathrm{O} 3$ (0001) interfaces revealed by first-principles
}

Agnes Mahmoud, Pierre-Marie Deleuze, Céline Dupont

\section{To cite this version:}

Agnes Mahmoud, Pierre-Marie Deleuze, Céline Dupont. The nature of the $\mathrm{Pt}(111) / \alpha$-Fe 2 O 3 (0001) interfaces revealed by first-principles. Journal of Chemical Physics, 2018, 148, pp.204701. 10.1063/1.5033366 . hal-03032731

\section{HAL Id: hal-03032731 https://hal.science/hal-03032731}

Submitted on 1 Dec 2020

HAL is a multi-disciplinary open access archive for the deposit and dissemination of scientific research documents, whether they are published or not. The documents may come from teaching and research institutions in France or abroad, or from public or private research centers.
L'archive ouverte pluridisciplinaire HAL, est destinée au dépôt et à la diffusion de documents scientifiques de niveau recherche, publiés ou non, émanant des établissements d'enseignement et de recherche français ou étrangers, des laboratoires publics ou privés. 
The nature of the $\mathrm{Pt}(111) / \alpha-\mathrm{Fe}_{2} \mathrm{O}_{3}(0001)$ interfaces revealed by first-principles

Agnes Mahmoud, ${ }^{1}$ Pierre-Marie Deleuze, ${ }^{1}$ and Celine Dupont ${ }^{1, \text { a) }}$

Laboratoire Interdisciplinaire Carnot de Bourgogne (ICB), UMR 6303 CNRS, Université Bourgogne Franche-Comté, BP 47870, 21078 Dijon Cedex,

France

Quantum-chemical ab initio calculations are performed to give a thorough description of structural, energetic and electronic properties of $\mathrm{Pt}(111) / \alpha-\mathrm{Fe}_{2} \mathrm{O}_{3}(0001)$ systems by spin-polarized density functional theory, accounting for the on-site Coulomb interaction. Towards the better understanding of $\mathrm{Pt}(111) / \alpha-\mathrm{Fe}_{2} \mathrm{O}_{3}(0001)$ interfaces, two terminations of $\alpha-\mathrm{Fe}_{2} \mathrm{O}_{3}(0001)$ surface, namely the single $\mathrm{Fe}$ - and the $\mathrm{O}_{3}$-termination, are considered and coupled with the four possible (top, hcp, fcc, bridge) sites on $\operatorname{Pt}(111)$. The effect of the strain on clean hematite surfaces due to the lattice mismatch between the substrate and the overlayer is included in the analysis. Among the possible adsorption configurations, bridge sites are unstable, while the most favorable configurations are the ones at hollow sites. The stability of the interfaces is not only influenced by the termination of the overlayer but also by the degree of its structural relaxation and the relative position of the first layer of $\mathrm{O}$ atoms in hematite with respect to $\mathrm{Pt}$. To elucidate the different nature of the two terminations of the overlayer on Pt, projected density of states and 3D charge density difference plots are also discussed.

a) Electronic mail: celine.dupont@u-bourgogne.fr 


\section{INTRODUCTION}

Metal-oxides have attracted much attention in the last decades and still play an important role in the development of novel electrochemical devices as they are promising functional materials for photoelectrochemical (PEC) water splitting. ${ }^{1-5}$

Hematite $\left(\alpha-\mathrm{Fe}_{2} \mathrm{O}_{3}\right)$ has been considered to be one of the most promising photoanode due to its favorable band gap $(\sim 2.2 \mathrm{eV})$ for visible light absorption, exceptional stability, low cost, and natural abundance. ${ }^{6}$ Despite all these positive aspects, it has low conductivity, high recombination rate and external bias is needed to promote water splitting due to the improper conduction band alignment. ${ }^{7}$ Several strategies have been addressed to com-

pensate such drawbacks including elemental doping attempts, ${ }^{8-13}$ complex heterostructure fabrications ${ }^{14-16}$ and nanostructuring to improve charge transport properties. ${ }^{17,18}$

Several experimental ${ }^{2-4,6,19-21}$ and theoretical investigations ${ }^{19,22-35}$ have been devoted to unravel the stability and reactivity of $\alpha-\mathrm{Fe}_{2} \mathrm{O}_{3}(0001)$ surfaces. A part of the above-mentioned studies have mainly focused on structural characterization of different terminations of such surfaces. ${ }^{19,20,22-26,36}$ Additionally, computational investigations were dedicated to understand water adsorption and dissociation on pure ${ }^{27-30,35}$, defective ${ }^{31,32}$ and doped $\alpha-\mathrm{Fe}_{2} \mathrm{O}_{3}(0001)$ surfaces $^{33,34}$ at molecular level.

However, hematite thin films are rarely used alone, but in a presence of conductive substrates. $\mathrm{Pt}(111)$ surface is often used as a substrate for $\alpha-\mathrm{Fe}_{2} \mathrm{O}_{3}(0001)$ thin film growth, because it is chemically inert, allows good epitaxy conditions and ensure conductive backcontact to improve the PEC activity in electrochemical devices. ${ }^{10,21,37-40}$ It is thus mandatory to determine the effect of $\mathrm{Pt}(111)$ substrate over hematite. In order to gather information about the chemical, structural and electronic properties in such interfaces, a molecular level investigation is required. Despite numerous studies reported on $\alpha$-hematite growth, mainly experimental ${ }^{10,21,37,41,42}$, but also some theoretical about sandwiched hematite ${ }^{39,40}$, the substrate-overlayer interface has not been resolved. In particular the termination (Feor $\mathrm{O}_{3}$ ) of hematite interacted with platinum is not well-known. However, to optimize the use of deposited hematite thin films, it is necessary to know the nature, the stability and the electronic characteristics of the $\mathrm{Pt}(111) / \alpha-\mathrm{Fe}_{2} \mathrm{O}_{3}(0001)$ interface.

In this work, we present a detailed analysis of the energetics, equilibrium geometries and electronic structures of epitaxially grown $\mathrm{Pt}(111) / \alpha-\mathrm{Fe}_{2} \mathrm{O}_{3}(0001)$ systems. Both termina- 
tions of $\alpha-\mathrm{Fe}_{2} \mathrm{O}_{3}(0001)$, namely the $\mathrm{Fe}$ - and the $\mathrm{O}_{3}$-termination, are investigated, in the four possible adsorption sites (top, hcp, fcc, bridge) on $\operatorname{Pt}(111)$.

\section{METHODS}

\section{A. Computational Details}

Spin-polarized DFT calculations based on plane-wave basis set of $550 \mathrm{eV}$ cutoff energy were performed with the Vienna ab initio simulation package VAsP. ${ }^{43,44}$ The electron-ion interaction was described within the projector-augmented plane-wave (PAW) method. ${ }^{45}$ Eight valence electrons were explicitly treated for $\mathrm{Fe}\left(3 \mathrm{~d}^{7} 4 \mathrm{~s}^{1}\right)$, six for $\mathrm{O}\left(2 \mathrm{~s}^{2} 2 \mathrm{p}^{4}\right)$ and ten for $\mathrm{Pt}$ $\left(5 \mathrm{~d}^{9} 6 \mathrm{~s}^{1}\right)$. For all calculations the general gradient approximation (GGA) with Perdew-BurkeErnzerhof exchange-correlation functional $(\mathrm{PBE})^{46}$ was employed. The DFT $+\mathrm{U}$ approach was adopted for the inclusion of the on-site Coulomb repulsion of Fe $3 \mathrm{~d}$ electrons using the Dudarev approach, ${ }^{47}$ with the effective parameter $\mathrm{U}_{\mathrm{eff}}=4.3 \mathrm{eV}$.

The Brillouin zone was sampled with a 8 × 8 x 1 Monkhorst-Pack $k$-point mesh in each heterostructure and gaussian smearing with the smearing width $\sigma=0.1$ was used to improve convergence. For density of states (DOS) calculations a denser $k$-mesh $16 \times 16$ x 1 and the tetrahedron method with Blöchl correction was employed. ${ }^{48}$

Full structural optimization was carried out until the forces converged below $0.01 \mathrm{eV} / \AA$. For hematite sufaces all atoms were allowed to relax, while in the hybrid models the bottom two Pt layers were frozen to the Pt bulk structure. The convergence threshold on total energy was set to $10^{-6} \mathrm{eV}$.

Slab models were applied to describe all heterostructures and their subunits. They were separated from their periodic images by a vacuum region of $20 \AA$.

In the following, the surface energies per surface area $(S)$ are given by

$$
\begin{aligned}
\gamma & =\frac{1}{2 \mathrm{~S}}\left(\mathrm{E}_{\text {slab }}-\mathrm{E}_{\text {bulk }}\right)= \\
& =\frac{1}{2 \mathrm{~S}}\left[\mathrm{E}_{\text {slab }}-\frac{1}{2} \mathrm{~N}_{\mathrm{Fe}_{\mathrm{e}}} \mu_{\mathrm{Fe}_{2} \mathrm{O}_{3}}+\left(\frac{3}{2} \mathrm{~N}_{\mathrm{Fe}}-\mathrm{N}_{\mathrm{O}}\right) \mu_{\mathrm{O}}\right]
\end{aligned}
$$

where $\mathrm{E}_{\text {slab }}$ and $\mathrm{E}_{\mathrm{bulk}}$ are the total energies of the slab and the bulk structure, respectively. The factor 2 accounts for the two identical surfaces. $\mathrm{N}_{\mathrm{Fe}}$ and $\mathrm{N}_{\mathrm{O}}$ are the number of iron and oxygen atoms in the slab, respectively. $\mu_{\mathrm{Fe}_{2} \mathrm{O}_{3}}$ is the chemical potential of bulk hematite 
per formula unit. The chemical potential of oxygen $\mu_{\mathrm{O}}$ is calculated as the half of the total energy of an isolated $\mathrm{O}_{2}$ molecule.

To characterize the interaction between the substrate and the overlayer, interaction energies (per surface unit S) were calculated according to the following equation:

$$
\Delta \mathrm{E}_{\mathrm{int}}=\frac{\mathrm{E}_{\mathrm{Pt} / \mathrm{Fe}_{2} \mathrm{O}_{3}}-\mathrm{E}_{\mathrm{Fe}_{2} \mathrm{O}_{3}}-\mathrm{E}_{\mathrm{Pt}}}{\mathrm{S}}
$$

where $\mathrm{E}_{\mathrm{Pt} / \mathrm{Fe}_{2} \mathrm{O}_{3}}$ is the total energy of the heterostructure, $\mathrm{E}_{\mathrm{Fe}_{2} \mathrm{O}_{3}}$ is the total energy of the strained $\alpha$-hematite(0001) overlayer and $\mathrm{E}_{\mathrm{Pt}}$ is the total energy of the $\mathrm{Pt}(111)$ substrate.

\section{B. Structural models}

The structural, electronic and different possible antiferromagnetic arrangements of bulk $\alpha$-hematite have been extensively studied by Rollmann et al. ${ }^{49}$ Two really important conclusions were made in this study. Firstly, the inclusion of the Hubbard parameter in DFT calculations is essential to describe the proper O $2 p$ - Fe $3 d$ charge-transfer gap. Secondly, they evidenced that the most stable structure is the antiferromagnetic configuration, which agrees with the experimental studies. This will be thus used in the following (see below).

For the formation of $\mathrm{Pt}(111) / \alpha-\mathrm{Fe}_{2} \mathrm{O}_{3}$ interfaces, the optimized crystallographic hexagonal unit cell of bulk $\alpha$-hematite with lattice constants of $\mathrm{a}_{\mathrm{Fe}_{2} \mathrm{O}_{3}}=5.066 \AA$ and $\mathrm{C}_{\mathrm{Fe}_{2} \mathrm{O}_{3}}=13.868$ $\AA$ is cut along the [0001] direction, where $\mathrm{Fe}$ and $\mathrm{O}_{3}$ layers are alternating. From all the possible $\alpha-\mathrm{Fe}_{2} \mathrm{O}_{3}(0001)$ surface terminations, we consider the single $\mathrm{Fe}$ - and $\mathrm{O}_{3}$-terminated surfaces in our predicted hybrid models. Our structural models for Fe- and $\mathrm{O}_{3}$-terminated surfaces are based on 18-layers and 19-layers symmetrical slabs (having the same termination at the top and at the bottom), respectively (see FIG. 1. for further details). The models are realized in order to keep the antiferromagnetism in the unit cell. In FIG. 1. blue and golden yellow spheres emphasize the most stable antiferromagnetic configuration previously established in the bulk structure. ${ }^{49}$ Keeping antiferromagnetism in $\alpha$ - $\mathrm{Fe}_{2} \mathrm{O}_{3}(0001)$ surfaces is not only a practical choice, but is above all related to an experimental observation of the absence of the Morin phase in nanometric $\mathrm{Fe}_{2} \mathrm{O}_{3}$ layers deposited on $\mathrm{Pt}(111) .{ }^{37}$

The substrate is modeled by a 5-layers $\mathrm{Pt}(111)$ slab with $\sqrt{3} \times \sqrt{3}$ unit cell $\left(\mathrm{a}_{\mathrm{Pt}}=4.863\right.$ $\AA$ ), in which the last two layers are fixed in a bulk-like geometry during relaxation.

Eight possible heterostructures are modeled through one-sided epitaxial relation by cou- 


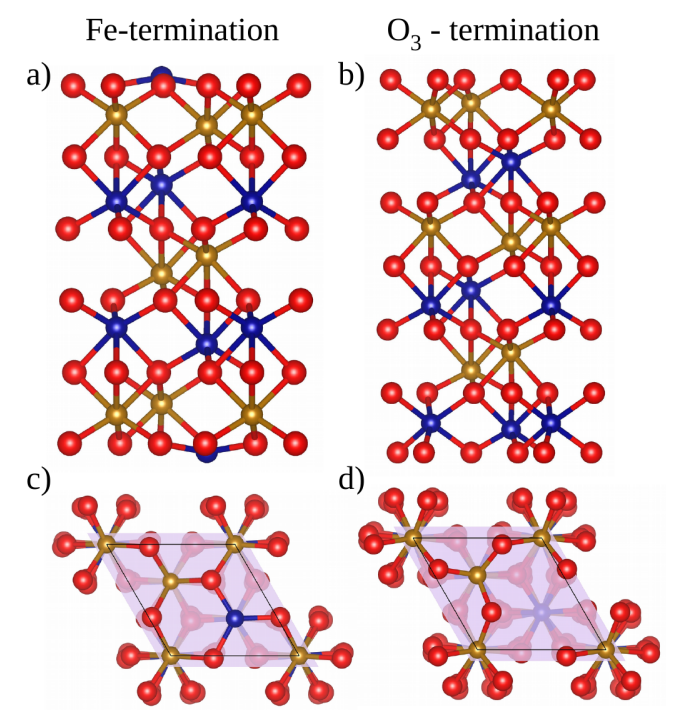

FIG. 1. Applied structural models of $\alpha-\mathrm{Fe}_{2} \mathrm{O}_{3}(0001)$ surfaces. Side [a), b)] and top view [c), d)] of 18-layers Fe-terminated and 19-layers $\mathrm{O}_{3}$-terminated surfaces, respectively. Red spheres denote $\mathrm{O}$ atoms, while blue and golden yellow spheres stand for Fe atoms. The two different color of Fe atoms represent the most stable antiferromagnetic ordering in $\alpha$-hematite.

pling the four possible sites in $\mathrm{Pt}(111)$ surface and the overlayer of $\alpha-\mathrm{Fe}_{2} \mathrm{O}_{3}(0001)$ (considering either $\mathrm{Fe}$ or $\mathrm{O}_{3}$ terminations). In Fe-terminated heterostructures, the adsorption sites of $\mathrm{Pt}$ are combined with the outmost Fe atom of hematite. On the other hand, $\mathrm{O}_{3}$-terminated can be seen as the single Fe-terminated surface where the outmost Fe atom has been removed and thus corresponds to a vacancy. Therefore in the following, adsorption positions for the $\mathrm{O}_{3}$-termination will correspond to the combination of adsorption sites of $\mathrm{Pt}$ with these vacancies (see FIG. 1 d)).

\section{RESULTS AND DISCUSSION}

\section{A. The overlayer: $\alpha-\mathrm{Fe}_{2} \mathrm{O}_{3}(0001)$ surfaces}

During the growth process of thin films, the occurring strain between the substrate and the overlayer needs to be taken into account, since such effect influences the stability of the interface. In order to achieve an epitaxial relation between $\alpha-\mathrm{Fe}_{2} \mathrm{O}_{3}(0001)$ and $\mathrm{Pt}(111)$, a $\sqrt{3} \times \sqrt{3}\left(\mathrm{a}_{\mathrm{Pt}}=\mathrm{b}_{\mathrm{Pt}}=4.863 \AA\right) 2 \mathrm{D}$ bidimensional unit cell of the former surface was 
$\operatorname{Pt}(111) \sqrt{ } 3 \times \sqrt{3}$

a)

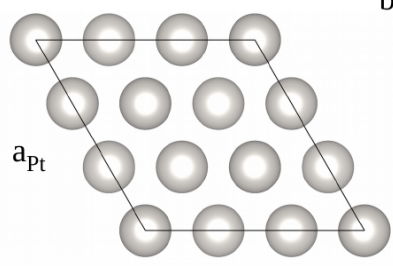

$\mathrm{b}_{\mathrm{Pt}}=\mathrm{a}_{\mathrm{Pt}}=4.8683$
$\alpha-\mathrm{Fe}_{2} \mathrm{O}_{3}(0001)$

b)

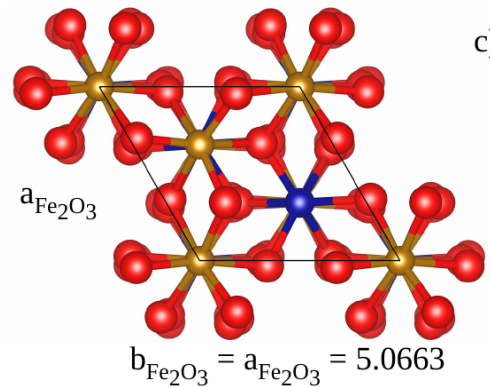

$\mathrm{Pt}(111) / \alpha-\mathrm{Fe}_{2} \mathrm{O}_{3}(0001)$

c)

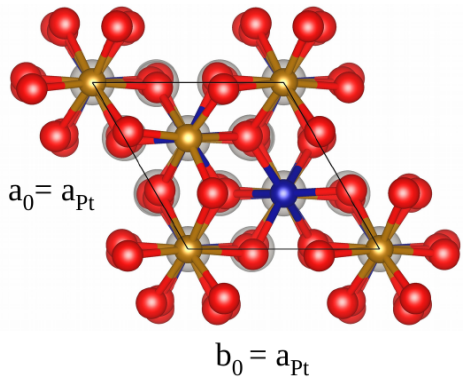

FIG. 2. In-plane lattice parameters of $\mathrm{Pt}(111)$ and $\alpha-\mathrm{Fe}_{2} \mathrm{O}_{3}(0001)$ surfaces [a), b)] used in the predicted $\mathrm{Pt}(111) / \alpha-\mathrm{Fe}_{2} \mathrm{O}_{3}(0001)$ heterostructures $\left.[\mathrm{c})\right]$. Grey spheres stand for $\mathrm{Pt}$ atoms, red spheres denote $\mathrm{O}$ atoms, while blue and golden yellow spheres represent $\mathrm{Fe}$ atoms. The two different color of Fe atom emphasize the antiferromagnetic configuration in the structure. In-plane lattice parameters of $\mathrm{Pt}(111)$ and $\alpha-\mathrm{Fe}_{2} \mathrm{O}_{3}(0001)$ surfaces are denoted as apt, $\mathrm{b}$ Pt and $\mathrm{aFe}_{2} \mathrm{O}_{3} \mathrm{~b}_{\mathrm{Fe}_{2} \mathrm{O}_{3}}$, respectively. The lattice parameters of the $\mathrm{Pt}(111) / \alpha-\mathrm{Fe}_{2} \mathrm{O}_{3}(0001)$ heterostructure are represented by $\mathrm{a}_{0}$ and $\mathrm{b}_{0}$.

employed. This kind of coincidence cell was also observed experimentally. ${ }^{10,37}$ For bulk-like $\alpha-\mathrm{Fe}_{2} \mathrm{O}_{3}(0001)$ surface, the bidimensional lattice parameters are $\mathrm{a}_{\mathrm{Fe}_{2} \mathrm{O}_{3}}=\mathrm{b}_{\mathrm{Fe}_{2} \mathrm{O}_{3}}=5.066 \AA$. Matching the $\alpha-\mathrm{Fe}_{2} \mathrm{O}_{3}(0001)$ surface with the $\mathrm{Pt}(111)$ substrate requires that $\mathrm{a}_{0}=\mathrm{b}_{0}=$ $\mathrm{a}^{\prime}{ }_{\mathrm{Fe}_{2} \mathrm{O}_{3}}=\mathrm{a}_{\mathrm{Pt}}=4.863 \AA$, where $\mathrm{a}_{0}$ and $\mathrm{b}_{0}$ are the lattice parameters of the heterostructure and $\mathrm{a}^{\prime} \mathrm{Fe}_{2} \mathrm{O}_{3}$ is the lattice parameter of constrained hematite surfaces. As a consequence, the applied smallest possible coincidence cell induces a $4.1 \%$ of compressive strain in $\alpha$ $\mathrm{Fe}_{2} \mathrm{O}_{3}(0001)$ surfaces (see FIG.2).

Before getting into the details of the structural and electronic properties of $\operatorname{Pt}(111) / \alpha$ $\mathrm{Fe}_{2} \mathrm{O}_{3}(0001)$ heterostructures, let us discuss first the structural and electronic properties of $\alpha$-hematite(0001) surfaces alone and their constrained counterparts. In the following, unstrained hematite surfaces refer to slabs cut directly out from the bulk structure and constrained configurations are the ones with the unit cell fixed at the $\operatorname{Pt}(111)$ substrate parameters. Huang et al. ${ }^{26}$ summarized the experimentally observed and theoretically predicted surfaces of $\alpha-\mathrm{Fe}_{2} \mathrm{O}_{3}(0001)$. The surfaces grown on Pt or Mo substrate exhibit only Fe-terminated or mixed Fe-and O-terminated surfaces. ${ }^{21,41,42,50}$ In view of the above, extending the investigation for both $\mathrm{Fe}$-and $\mathrm{O}_{3}$-terminations of $\alpha-\mathrm{Fe}_{2} \mathrm{O}_{3}(0001)$ in $\mathrm{Pt} / \alpha-\mathrm{Fe}_{2} \mathrm{O}_{3}$ 
systems can be a crucial point for a better understanding of the growth mechanism and the interfacial stability in such heterostructures.

The theoretical determination of surface stability of different terminations of isolated $\alpha$ $\mathrm{Fe}_{2} \mathrm{O}_{3}(0001)$ surface has been an object of strong interest and is still under discussion mainly due to chemical environmental dependence of the on-site Coulomb interactions. ${ }^{19,24-26,51,52}$ In this study (see Section Computational Details for further details), we used a previously successfully applied optimized $\mathrm{U}_{\text {eff }}$ value for hematite, which predicts ground and excited states properties in good agreement with experiments. ${ }^{33,36,53}$ Surface energies computed at GGA $+\mathrm{U}$ level ${ }^{23,24,31,32}$ suggests that the single Fe-terminated surface is more stable than $\mathrm{O}_{3}$-terminated one in a wide range of oxygen chemical potential. We computed the surface energies of the two terminations at oxygen-rich environment (when $\Delta \mu_{\mathrm{O}}=\frac{1}{2} \mathrm{E}_{\mathrm{O}_{2}}-\mu_{\mathrm{O}}$ (see Eq.1) $)$ and the obtained values $\left(\gamma_{\text {Fe-term }}=70.83 \mathrm{meV} / \AA^{2}\right.$ and $\left.\gamma_{\mathrm{O}_{3} \text {-term }}=143.78 \mathrm{meV} / \AA^{2}\right)$ are in line with the previous statement.

Let us now discuss the computed structural, electronic and magnetic properties of bulk $\alpha$-hematite, and of unstrained and constrained $\alpha$ - $\mathrm{Fe}_{2} \mathrm{O}_{3}(0001)$ surfaces reported in TABLE I. In FIG. 3. we also report the graphical representation of interplanar relaxations of the unstrained and constrained surfaces of $\alpha$-hematite comparing with previous experimental $^{19,20}$ and theoretical ${ }^{24}$ studies. After structural optimization, in the unstrained single Fe-terminated surface, consecutive interplanar distances show a contraction-expansion alternating pattern with respect to the bulk values.

The outmost under-coordinated Fe atom almost relaxes inwards to the $\mathrm{O}_{3}$ plane, resulting in a contraction of $69 \%$ of the first $\mathrm{d}_{\mathrm{Fe}-\mathrm{O}_{3}}$ interlayer distance with respect to the bulk (see also FIG. 1). The interplanar relaxations are mainly manifested between the first 5 layers of the structure, while in the middle planes the bulk values are reproduced. Our computed values are in line with the ones obtained by Kiejna et $a .^{24}$ and show a qualitatively good agreement with experimental data ${ }^{20}$ (see FIG. 3 a)). The interplanar displacement pattern is not much changed in the constrained Fe-terminated surface. However, due to the compressive strain the outmost iron atom moves towards the surface with respect to the unstrained slab and the introduced strain does not allow to relax the structure to bulk values, but emphasizes the interplanar deviations with additional $7 \%$, with respect to the bulk values.

In the unstrained $\mathrm{O}_{3}$-terminated surface the first layer slightly moves inwards with re- 


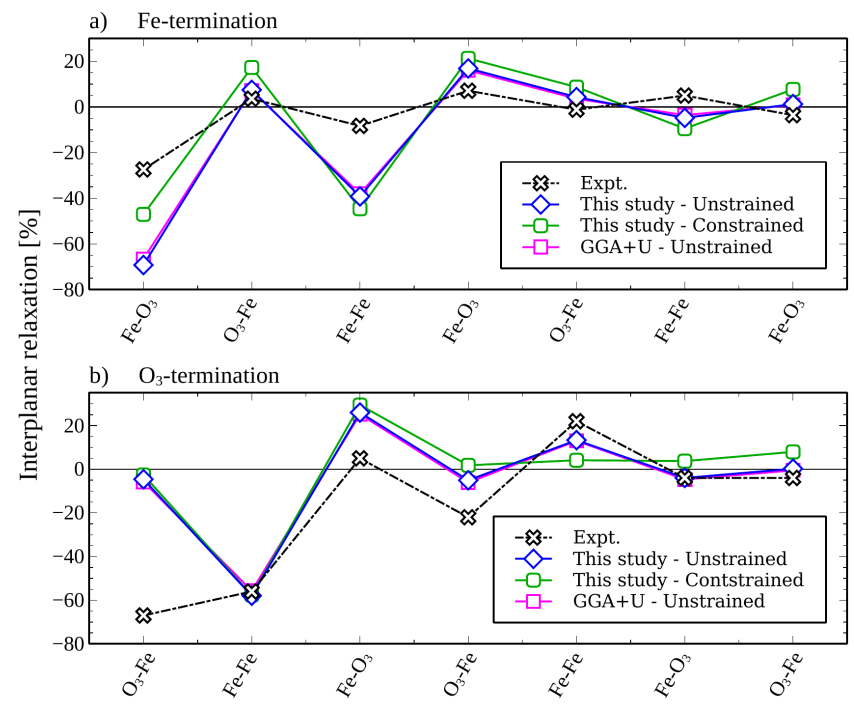

FIG. 3. Interplanar relaxations [in \%] for unstrained and constrained Fe-and $\mathrm{O}_{3}$-terminated $\alpha$ $\mathrm{Fe}_{2} \mathrm{O}_{3}(0001)$ surfaces in comparison with previous experimental ${ }^{19,20}$ and theoretical ${ }^{24}$ investigations.

spect to the bulk, this agrees well with the interplanar relaxation calculated by Kiejna et $a l .{ }^{24}$ However, the experimentally observed data ${ }^{19}$ show a large contraction of $67 \%$ of the first layer of the $\mathrm{O}_{3}$-terminated surface (see FIG 3 b)). This discrepancy between computed values and experimental data has not yet been elucidated. A significant interplanar contraction appears between the Fe-Fe bilayer close to the surface $\left(\mathrm{d}_{\mathrm{Fe}-\mathrm{Fe}}=0.241 \AA\right.$, instead of $0.574 \AA$ in the bulk), which itself induces an interplanar expansion of the consecutive layer $\left(\mathrm{d}_{\mathrm{Fe}-\mathrm{O}_{3}}=1.095 \AA\right)$. After all, the interplanar distances relax versus the bulk values. From the second layer the interplanar relaxation shows an overall good agreement with experiments (see FIG 3 b)). Comparing the unstrained and constrained surfaces, the differences for the first three interlayer distances are rather small. However, it becomes more significant approaching the central layers, where the previously mentioned $7 \%$ additional deviation can also be observed.

The change in magnetic moments and electronic structure is highly correlated to the lowcoordinated surface atoms. In the unstrained Fe-terminated surface the magnetic moment of the topmost $\mathrm{Fe}$ atom shows only a modest reduction, while in the $\mathrm{O}_{3}$-terminated surface the reductions in the Fe-Fe bilayer are more evident. The magnetic moments of the central layers have relaxed towards the bulk value. In the constrained configurations the magnetic 
TABLE I. Computed structural electronic and magnetic properties of bulk $\alpha$-hematite, unstrained and constrained $\alpha-\mathrm{Fe}_{2} \mathrm{O}_{3}(0001)$ surfaces. Unstrained surfaces stand for surfaces cut directly out from the bulk structure. Constrained surfaces refer to overlayers with the lattice parameters fixed to the ones of $\operatorname{Pt}(111)$ substrate $(\mathrm{a}=4.863 \AA)$. Interplanar distances $[d]$ are in $\AA$, absolute value of magnetic moments of $\mathrm{Fe}$ atoms $\left[\left|\mu_{\mathrm{Fe}}\right|\right]$ are in $\mu_{\mathrm{B}}$ and electronic band gaps $\left[\mathrm{E}_{\mathrm{g}}\right]$ are in $\mathrm{eV}$. $\Delta \mathrm{E}_{\text {strain }}$ refers to the strain energy in $\mathrm{meV} / \AA^{2}$ defined as the energy difference between a relaxed and constrained overlayer per unit area. Interplanar distances and magnetic moments are reported from the surface until the middle of the slabs. Numeration starts from the surface of the slabs. $\mathrm{d}_{\mathrm{Fe}-\mathrm{O}_{3}}$ and $\mathrm{d}_{\mathrm{O}_{3}-\mathrm{Fe}}$ are the first interplanar distances for Fe- and $\mathrm{O}_{3}$-termination, respectively (see also FIG. 1). Values in parentheses are experimentally observed magnetic moment ${ }^{54}$ and optical band gap $^{55}$ of bulk hematite

\begin{tabular}{|c|c|c|c|c|c|}
\hline & \multirow[t]{2}{*}{ Bulk } & \multicolumn{2}{|c|}{ Fe-termination } & \multicolumn{2}{|c|}{$\mathrm{O}_{3}$-termination } \\
\hline & & Unstrained & Constrained & Unstrained & d Constrained \\
\hline $\mathrm{d}_{\mathrm{Fe}-\mathrm{Fe}}$ & 0.574 & 0.597 & 0.531 & 0.565 & 0.513 \\
\hline $\mathrm{d}_{\mathrm{O}_{3}-\mathrm{Fe}}$ & 0.869 & 0.857 & 0.930 & 0.871 & 0.938 \\
\hline $\mathrm{d}_{\mathrm{Fe}-\mathrm{O}_{3}}$ & 0.869 & 0.880 & 0.936 & 0.834 & 0.901 \\
\hline$d_{\mathrm{Fe}-\mathrm{Fe}}$ & & 0.546 & 0.519 & 0.650 & 0.597 \\
\hline $\mathrm{d}_{\mathrm{O}_{3}-\mathrm{Fe}}$ & & 0.906 & 0.944 & 0.825 & 0.884 \\
\hline $\mathrm{d}_{\mathrm{Fe}-\mathrm{O}_{3}}$ & & 1.016 & 1.054 & 1.095 & 1.124 \\
\hline$d_{\mathrm{Fe}-\mathrm{Fe}}$ & & 0.349 & 0.318 & 0.241 & 0.234 \\
\hline $\mathrm{d}_{\mathrm{O}_{3}-\mathrm{Fe}}$ & & 0.934 & 1.019 & 0.829 & 0.846 \\
\hline $\mathrm{d}_{\mathrm{Fe}-\mathrm{O}_{3}}$ & & 0.267 & 0.460 & - & - \\
\hline$\left|\mu_{\mathrm{Fe}_{6}}\right|$ & 4.188 & 4.187 & 4.158 & 4.186 & 4.157 \\
\hline$\left|\mu_{\mathrm{Fe}_{5}}\right|$ & $\left(4.9^{54}\right)$ & 4.185 & 4.155 & 4.183 & 4.153 \\
\hline$\left|\mu_{\mathrm{Fe}_{4}}\right|$ & & 4.184 & 4.157 & 4.186 & 4.157 \\
\hline$\left|\mu_{\mathrm{Fe}_{3}}\right|$ & & 4.197 & 4.165 & 4.198 & 4.170 \\
\hline$\left|\mu_{\mathrm{Fe}_{2}}\right|$ & & 4.173 & 4.150 & 3.864 & 3.755 \\
\hline$\left|\mu_{\mathrm{Fe}_{1}}\right|$ & & 4.036 & 3.982 & 2.954 & 2.913 \\
\hline $\mathrm{E}_{\mathrm{g}}$ & $\begin{array}{c}2.30 \\
\left(2.2^{55}\right)\end{array}$ & 1.56 & 1.42 & - & - \\
\hline$\Delta \mathrm{E}_{\text {strain }}$ & & & 6.28 & & 1.65 \\
\hline
\end{tabular}




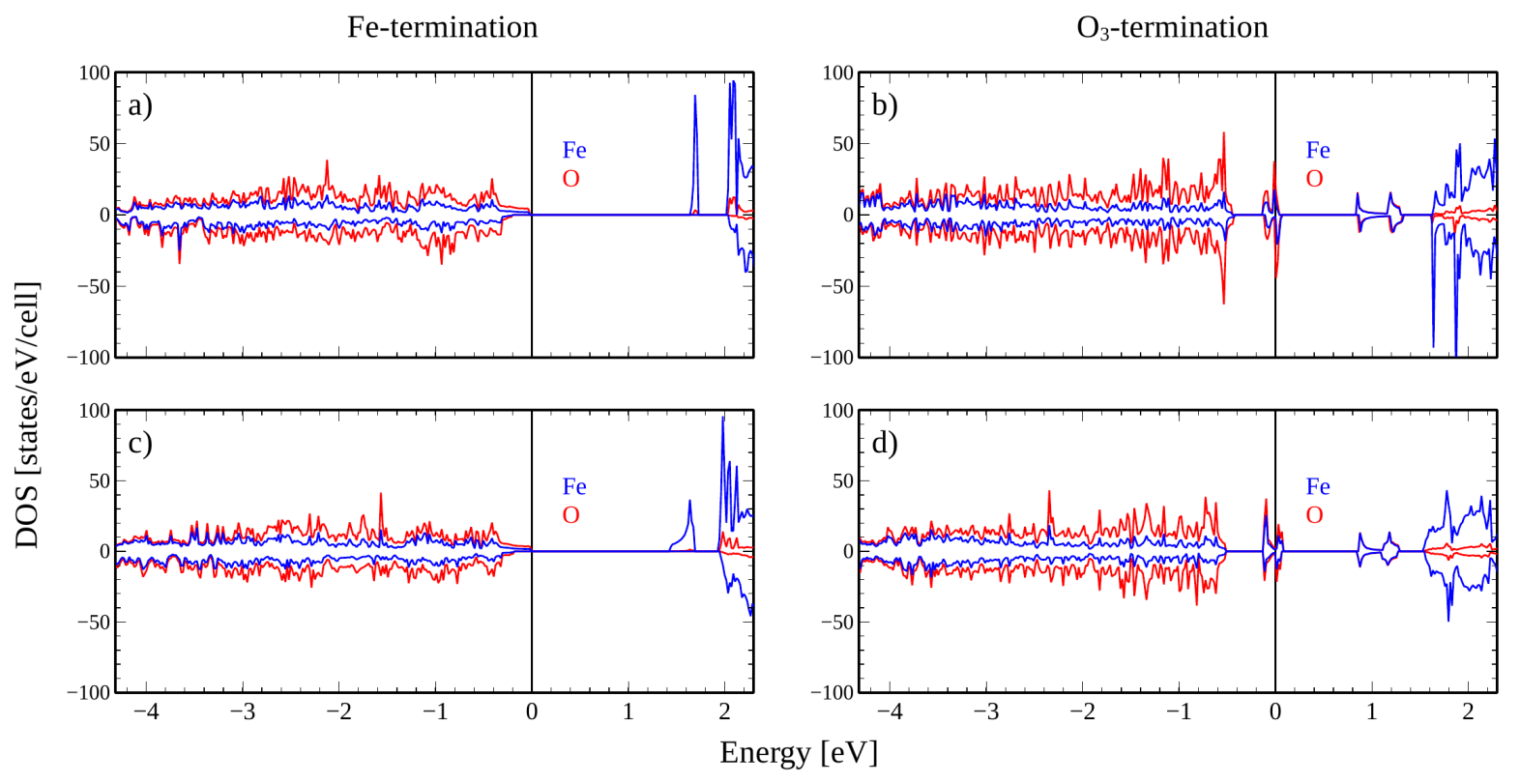

FIG. 4. Projected density of states of unstrained [a), b)] and constrained [c), d)] Fe-and $\mathrm{O}_{3}$ surface terminations of $\alpha-\mathrm{Fe}_{2} \mathrm{O}_{3}(0001)$, respectively. Unstrained surfaces stand for surfaces cut directly out from the bulk structure. Constrained surfaces refer to overlayers with the lattice parameters fixed to the ones of $\operatorname{Pt}(111)$ substrate $(\mathrm{a}=4.863 \AA)$. Majority and minority spin states are displayed with positive and negative values. The top of the valence bands are indicated by vertical lines and set to zero.

moment reduction is only slightly more pronounced with respect to the unstrained surfaces and the magnetic moments of the central layers are very close to the bulk value (see TABLE I.)

In FIG. 4. we show the projected density of states (PDOSs) of unstrained (FIG. 4 a), b)) and constrained (FIG. 4 c), d)) Fe-and $\mathrm{O}_{3}$ surface terminations of $\alpha$-Fe $\mathrm{O}_{3}(0001)$, respectively. The unstrained Fe-terminated surface shows a reduced gap $(1.56 \mathrm{eV})$ with respect to the bulk $(2.3 \mathrm{eV})$. The first empty states are the surface states of $\mathrm{Fe}(3 d)$ located $1.56 \mathrm{eV}$ above the Fermi level $\left(\mathrm{E}_{\mathrm{F}}\right)$. Due to the compressive strain in the constrained Fe-terminated surface the surface states becomes broader, which leads to further reduction of the gap (1.42 $\mathrm{eV}$ ). The unstrained $\mathrm{O}_{3}$-terminated surface shows a metallic character with well-defined surface states of $\mathrm{O}(2 p)$ and $\mathrm{Fe}(3 d)$ at $\mathrm{E}_{\mathrm{F}}$. The PDOS of the constrained counterpart of this termination slightly shift downwards and the states at $\mathrm{E}_{\mathrm{F}}$ are also marginally broadened.

The applied strain affects differently the two terminations of $\alpha-\mathrm{Fe}_{2} \mathrm{O}_{3}(0001)$. This is 
clearly revealed from both the computed strain energies, $\Delta \mathrm{E}_{\text {strain }}$ (see TABLE I) and PDOSs. The $4.1 \%$ of compressive strain corresponds to an areal strain energy of 76.28 and 41.65 $\mathrm{meV} / \AA^{2}$ in $\mathrm{Fe}$-and $\mathrm{O}_{3}$-terminated surfaces, respectively. Even though the $\mathrm{O}_{3}$-terminated surface appears to be less stable, it is more resistant to the occurring strain, which is an important factor in heterostructure fabrication. Moreover, changes in electronic structure due to the strain in Fe-terminated surface are more notable (the surface states are more broadened), than in the $\mathrm{O}_{3}$-terminated slabs.

\section{B. The $\mathrm{Pt} / \mathrm{Fe}_{2} \mathrm{O}_{3}$ Interface}

The Fe-and $\mathrm{O}_{3}$-terminations of $\alpha-\mathrm{Fe}_{2} \mathrm{O}_{3}(0001)$ are now coupled with the four possible adsorption sites on Pt(111) (top, hollow hcp, hollow fcc and bridge site), leading to eight heterostructures. The initial adsorption configurations are defined with respect to the position of the topmost Fe atom in Fe-terminated or "Fe-vacancy" in $\mathrm{O}_{3}$-terminated $\alpha-\mathrm{Fe}_{2} \mathrm{O}_{3}(0001)$ surfaces, respectively (for further details see Subsection II B), towards the Pt(111) surface. During geometry optimization, the adsorption on the bridge site is unstable for both terminations of $\alpha-\mathrm{Fe}_{2} \mathrm{O}_{3}(0001)$ and migration towards the most stable positions is systematically observed. Therefore, bridge positions will be no more discussed in the following. The remained six optimized $\mathrm{Pt}(111) / \alpha-\mathrm{Fe}_{2} \mathrm{O}_{3}(0001)$ heterostructures are shown in FIG. 5. and FIG. 6., while computed interlayer displacements and interaction energies are reported in TABLE II.

Let us first discuss the Fe-terminated $\mathrm{Pt} / \mathrm{Fe}_{2} \mathrm{O}_{3}$ heterostructures (see FIG. 5.). According to the predicted interaction energies the preferred adsorption position corresponds to the hollow $f c c$ site $\left(\Delta \mathrm{E}_{\text {int }}^{\mathrm{Fcc}}=-51.04 \mathrm{meV} / \AA^{2}\right)$. However, the difference in energy with respect to the two other configurations is less than one order of magnitude $\left(\Delta \mathrm{E}_{\text {int }}^{\text {Top }}=\right.$ $40.48 \mathrm{meV} / \AA^{2}, \Delta \mathrm{E}_{\mathrm{int}}^{\mathrm{Hcp}}=-43.70 \mathrm{meV} / \AA^{2}$ ), indicating a competitivity between the different structures. It is clearly seen, that lower interaction energies (higher by absolute value) correspond to reduced interlayer distances between the substrate and overlayer $\left(d_{\mathrm{Pt}-\mathrm{Fe}\left(\alpha-\mathrm{Fe}_{2} \mathrm{O}_{3}\right)}^{\mathrm{Top}}\right.$ $\left.=2.546 \AA>\mathrm{d}_{\mathrm{Pt}-\mathrm{Fe}\left(\alpha-\mathrm{Fe}_{2} \mathrm{O}_{3}\right)}^{\mathrm{Hcp}}=2.293 \AA>\mathrm{d}_{\mathrm{Pt}-\mathrm{Fe}\left(\alpha-\mathrm{Fe}_{2} \mathrm{O}_{3}\right)}^{\mathrm{Fcc}}=2.137 \AA\right)$. In the Pt substrate, modifications of interplanar distances, with respect to the subunit relaxed alone remain under $1 \%$. However, at hollow $f c c$ site this interlayer spacing is somewhat more pronounced and the first Pt layer moves slightly towards the overlayer. Due to the reduced distance 
a)

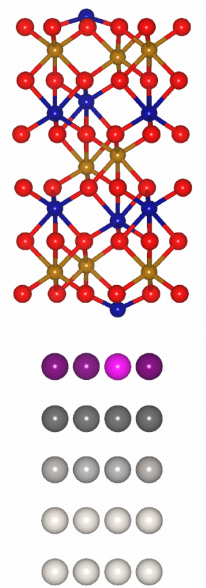

d)

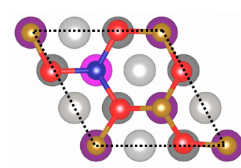

b)

e)

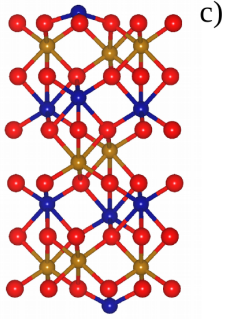

$\odot \odot \odot \odot$

○०००

○००

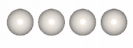

0000

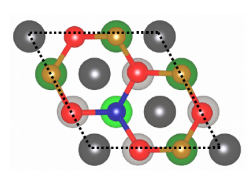

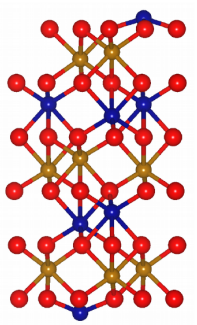

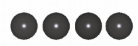

$\odot \odot \odot \odot$

๑०९

0000

0000

f)

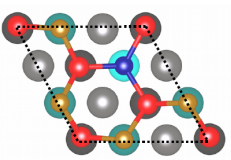

FIG. 5. Side views [a)-c)] and top views [d) - f)] of the optimized Fe-terminated heterostructures, for top [a),d)], hollow hcp [b),e)] and hollow fcc [c),f)], respectively. Different shades of grey stand for $\mathrm{Pt}$ atoms, red spheres denote $\mathrm{O}$ atoms, while blue and golden yellow spheres represent Fe atoms. The two different color of Fe atoms emphasize the antiferromagnetic configuration in the structure. The on top [a),c)], at hollow hcp [b),e)] and at hollow fcc [c),f)] adsorption sites in the corresponding Pt layer are highlighted with purple, green and turquoise color, respectively. The brighter color stands for the Pt atom directly exposed to the outmost Fe atom of hematite. In the top views, the first four layers of hematite and the first three layers of Pt are only shown.

between the substrate and the overlayer, the outmost Fe atom of hematite induces a Pt-Pt intralayer distance expansion at the hollow sites in the first layer of $\mathrm{Pt}(111)\left(\mathrm{d}_{\mathrm{Pt}-\mathrm{Pt}}^{\mathrm{Fcc}}=2.856\right.$ $\AA, \mathrm{d}_{\mathrm{Pt}-\mathrm{Pt}}^{\mathrm{Hcp}}=2.822 \AA, \mathrm{d}_{\mathrm{Pt}-\mathrm{Pt}}^{\mathrm{Bulk}}=2.81 \AA$ ). For hematite, the interlayer spacings are reported up to the middle of the overlayer. In all configurations, a significant interplanar expansion takes place between the first two layers of the overlayer. The most stable configuration exhibits the lowest expansion, while approaching the central layers it relaxes towards to values of the constrained subunit optimized without the substrate. Differently, adsorptions on top and at hollow hcp sites show greater expansion in the first two layers and a residual strain manifests up to seventh layer with respect to its constrained counterpart relaxed alone.

In comparison with Fe-terminated hybrid systems, the $\mathrm{O}_{3}$-terminated heterostructures 
TABLE II. Computed interplanar displacements $[d]$ in $\AA$ and interaction energies $\left[\Delta \mathrm{E}_{\text {int }}\right]$ and adhesion energies $\left[\Delta \mathrm{E}_{\text {adh }}\right]$ are in $\mathrm{meV} / \AA^{2}$ for the six $\operatorname{Pt}(111) / \alpha-\mathrm{Fe}_{2} \mathrm{O}_{3}(0001)$ interfaces. [] denotes the deviation in $\%$ of interplanar displacements between the optimized heterostructure and subunits relaxed alone. Numeration of the atomic planes starts from the interface.

Fe-termination

Top

Hcp

Fcc

Top

Hсp

Fcc

$$
\begin{array}{ccccccc}
\mathrm{d}_{67}-\alpha-\mathrm{Fe}_{2} \mathrm{O}_{3}(0001) & 0.548[5.52] & 0.548[5.53] & 0.529[1.95] & 0.906[0.98] & 0.903[0.23] & 0.920[2.06] \\
\mathrm{d}_{56}-\alpha-\mathrm{Fe}_{2} \mathrm{O}_{3}(0001) & 0.916[-3.02] & 0.916[-3.01] & 0.938[-0.69] & 0.547[0.54] & 0.564[-5.62] & 0.552[-7.54] \\
\mathrm{d}_{45}-\alpha-\mathrm{Fe}_{2} \mathrm{O}_{3}(0001) & 1.083[2.81] & 1.080[2.48] & 1.055[0.13] & 0.936[5.82] & 0.920[3.97] & 0.902[1.95] \\
\mathrm{d}_{34}-\alpha-\mathrm{Fe}_{2} \mathrm{O}_{3}(0001) & 0.291[-8.56] & 0.298[-6.26] & 0.306[-3.67] & 1.023[-9.04] & 1.061[-5.65] & 1.108[-1.44] \\
\mathrm{d}_{23}-\alpha-\mathrm{Fe}_{2} \mathrm{O}_{3}(0001) & 0.976[-4.29] & 0.966[-5.18] & 1.013[-0.63] & 0.328[35.06] & 0.284[16.89] & 0.306[26.16] \\
\mathrm{d}_{12}-\alpha-\mathrm{Fe}_{2} \mathrm{O}_{3}(0001) & 0.693[50.63] & 0.762[65.65] & 0.617[34.22] & 1.033[22.13] & 0.993[17.38] & 1.036[22.38]
\end{array}
$$

$\begin{array}{lllllll}\mathrm{d}_{12}-\operatorname{Pt}(111) & 2.317[-0.06] & 2.320[0.09] & 2.329[0.44] & 2.124[-8.39] & 2.255[-2.79] & 2.272[-1.98] \\ \mathrm{d}_{23}-\operatorname{Pt}(111) & 2.276[0.07] & 2.268[-0.29] & 2.264[-0.44] & 2.277[0.11] & 2.280[0.25] & 2.293[0.84] \\ \mathrm{d}_{34}-\operatorname{Pt}(111) & 2.271[-0.10] & 2.271[-0.10] & 2.256[-0.76] & 2.281[0.35] & 2.292[0.83] & 2.291[0.79]\end{array}$

$\begin{array}{lrrrrrr}\mathrm{d}_{\mathrm{Pt}-\mathrm{Fe}\left(\alpha-\mathrm{Fe}_{2} \mathrm{O}_{3}\right)} & 2.546 & 2.293 & 2.137 & 2.269 & 2.958 & 2.999 \\ \mathrm{~d}_{\mathrm{Pt}-\mathrm{O}_{3}\left(\alpha-\mathrm{Fe}_{2} \mathrm{O}_{3}\right)} & 3.239 & 3.055 & 2.754 & 1.236 & 1.970 & 1.959 \\ \Delta \mathrm{E}_{\text {int }} & -40.48 & -43.70 & -51.04 & -102.92 & -212.63 & -185.40 \\ \Delta \mathrm{E}_{\text {adh }} & 35.80 & 32.58 & 25.24 & -61.27 & -170.98 & -143.75\end{array}$


a)

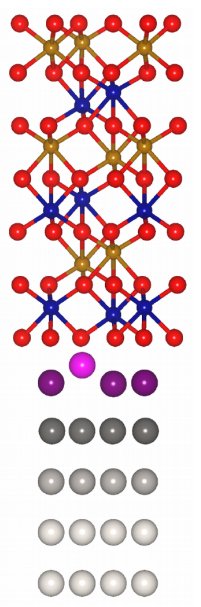

d)

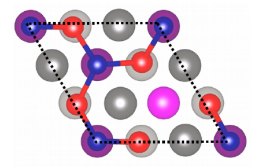

b)
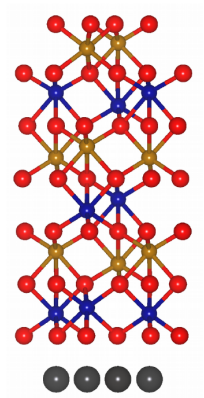

○०००

○००

0000

0000

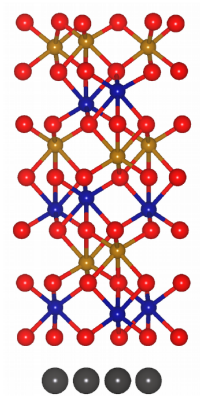

๑॰॰

○०॰०

0000

0000

f)
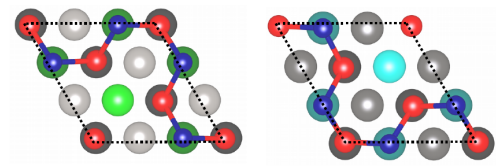

FIG. 6. Side views [a)-c)] and top views [d) - f)] of the optimized $\mathrm{O}_{3}$-terminated heterostructures. Bright purple, bright green and bright turquoise atoms indicate the position of $\mathrm{Pt}$ atoms at different adsorption sites coupled with "Fe-vacancy" in hematite. In the top views, the first three layers of hematite and Pt are only shown. For further explanation see caption of FIG. 5 and subsection II B.

(see FIG. 6.) predict significantly lower interaction energies, thus higher stability. The hollow hcp adsorption configuration is the most stable among them followed by the one at the hollow $f c c$ site and the less stable configuration is obtained on the top site $\left(\Delta \mathrm{E}_{\text {int }}^{\mathrm{Hcp}}=\right.$ $\left.-212.63 \mathrm{meV} / \AA^{2}>\Delta \mathrm{E}_{\text {int }}^{\mathrm{Fcc}}=-185.40 \mathrm{meV} / \AA^{2}>\Delta \mathrm{E}_{\text {int }}^{\mathrm{Top}}=-102.92 \mathrm{meV} / \AA^{2}\right)$. Upon adsorption on the top site of $\mathrm{Pt}(111)$, the "Fe-vacant layer" tries to reproduce the Fe-terminated surface by extracting the "on-top" Pt atom (see FIG. 6.a)), which results in a considerable interlayer reduction between the substrate and the overlayer $\left(\mathrm{d}_{\mathrm{Pt}_{-} \mathrm{O}_{3}\left(\alpha-\mathrm{Fe}_{2} \mathrm{O}_{3}\right)}=1.236 \AA\right)$. The distances between the two subunits in the other two optimized heterostructures are rather similar and the values are lower than in the most stable Fe-terminated heterostructure, which is in line with obtained adhesion energies. In Fe-terminated heterostructures, no significant change or more likely a tiny expansion are observed in first layer of Pt substrate. However, in the $\mathrm{O}_{3}$-terminated interfaces a well-defined interlayer compression can be noticed, while in deeper layers the inteplanar distances with respect to the subunit relaxed 
alone remain under $1 \%$. The $\mathrm{Fe}_{2} \mathrm{O}_{3}$ overlayer is mainly characterized by expansion of the first two interlayer spacings $\left(\mathrm{d}_{12}, \mathrm{~d}_{23}\right)$ with respect to the constrained surface optimized solo. Moreover, the most stable configuration corresponds to the smallest expansion.

So far, we considered the interaction energies in their entirety. However, to describe carefully the interface it can be interesting to introduce the adhesion energy with two components: one related to the strain applied to the overlayer $\left(\Delta \mathrm{E}_{\text {strain }}\right)$, the second related to the interaction of the strained hematite with the substrate $\left(\Delta \mathrm{E}_{\text {int }}\right)$, leading to: $\Delta \mathrm{E}_{\text {adh }}$ $=\Delta \mathrm{E}_{\text {strain }}+\Delta \mathrm{E}_{\text {int }}$. In the case of Fe-terminated heterostructures, none of the adhesion energies of the different configurations can compensate the occurring strain energy, $\Delta \mathrm{E}_{\text {strain }}$ $=76.28 \mathrm{meV} / \AA^{2}$. On the contrary, each $\mathrm{O}_{3}$-terminated systems can overcome the strain energy $\left(\Delta \mathrm{E}_{\text {strain }}=41.65 \mathrm{meV} / \AA^{2}\right)$, since the released energy is higher by absolute value and the occurring strain energy is lower.

Additionally, the cause of the interface stability is also related to the position of the $\mathrm{O}$ atoms and the degree of structural relaxation in the overlayer. In the most stable configurations, O atoms arranged on top of the Pt atoms are more favorable (see FIG. 5.d) - f) and FIG. 6.d) - f)) and the lesser interlayer spacings in the overlayer (especially in the first layers) are positively correlated to the computed adhesion energy (see TABLE II).

To confirm the stability of $\mathrm{O}_{3}$-termination of $\alpha-\mathrm{Fe}_{2} \mathrm{O}_{3}(0001)$ surface at hematite/Pt interfaces we also performed calculations on a heterostructure with asymmetric hematite slab (Fe-termination on top and $\mathrm{O}_{3}$-termination close to the interface) on Pt substrate. The structure was obtained by the removal of the interfacial Fe atom (at hollow $f c c \mathrm{Pt}$ site) from the most stable Fe-terminated heterostructure. In this case we obtained an interaction energy of - $188.01 \mathrm{meV} / \AA^{2}$, and the corresponding strain energy of the asymmetric hematite surface is $53.73 \mathrm{meV} / \AA^{2}$. This is clearly indicates that the formation of the heterostructure in question is favorable $\left(\Delta \mathrm{E}_{\mathrm{adh}}=-134.28 \mathrm{meV} / \AA^{2}\right)$ and comparing with the other predicted adhesion energies (see TABLE II) the asymetric hematite surface could also represent a competitive solution as an overlayer in hematite/Pt heterostructures.

To explore the change in electronic structure of $\alpha-\mathrm{Fe}_{2} \mathrm{O}_{3}(0001)$ and the charge redistribution at $\mathrm{Pt} / \mathrm{Fe}_{2} \mathrm{O}_{3}$ interfaces, PDOSs and 3D charge density difference plots are performed, and the results are depicted in FIG 7. and FIG. 8. The qualitative difference between the interfaces is related to the termination of the overlayer and the different adsorption sites in the substrate result only in quantitive changes. Therefore, for the sake of clarity and simplicity 


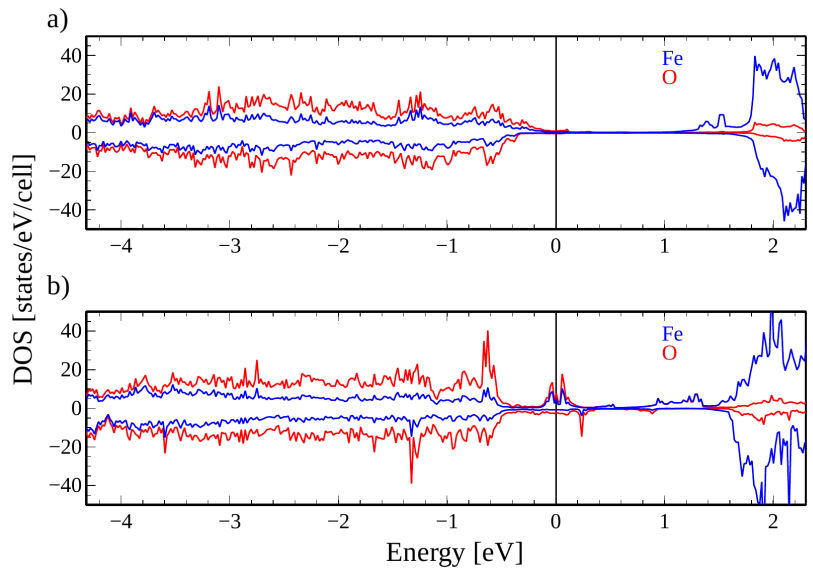

FIG. 7. Projected density of states on $\mathrm{Fe}$ and $\mathrm{O}$ of the most stable a) Fe (at hollow fcc site adsorption configuration) - and b) $\mathrm{O}_{3}$-terminated (at hollow hcp site adsorption configuration) $\mathrm{Pt} / \mathrm{Fe}_{2} \mathrm{O}_{3}$ heterostructures. Majority and minority spin states are displayed with positive and negative values. The top of the valence bands are indicated by vertical lines and set to zero.

PDOSs and charge density differences are reported only for the most stable configurations of Fe (at hollow fcc Pt site) - and $\mathrm{O}_{3}$-terminated (at hollow hcp Pt site) heterostructures. In FIG. 7 the DOSs are projected only on Fe and $\mathrm{O}$ atoms to emphasize the impact of Pt on the two different terminations of $\alpha$-hematite surfaces and the mid gap states of Pt are not reported for sake of clarity. It is clearly seen, that the Fe-terminated surface (FIG. 7. a)) is less perturbed by $\mathrm{Pt}$ with respect to the $\mathrm{O}_{3}$-terminated surface (FIG. 7. b)) if we compare with the constrained surfaces relaxed without the substrate (FIG. 4. c) d)). In the case of Fe-terminated heterostructure a slight change around the top of the valence band is observed due to the the weak hybridization between the $\mathrm{Fe}$ and $\mathrm{O}$ atoms of hematite close to the interface and Pt. The surface states related to the outmost Fe atoms are even more broadened with respect to the constrained counterpart relaxed alone and the gap is only marginally perturbed by $\mathrm{Pt}$. In the $\mathrm{O}_{3}$-terminated heterostructure, changes in electronic structure are more evident. For instance, in FIG. 4 d) no states are occupied between the energy range of -0.5 to $-0.1 \mathrm{eV}$, however these states are populated in the heterostructure. The surface states at the Fermi level are broadened indicating a strong hybridization between Fe and $\mathrm{O}$ of $\mathrm{O}_{3}$-terminated surface and $\mathrm{Pt}$. The level of hybridization between the substrate and the two different overlayers is in line with the computed adhesion energies, more precisely, the more pronounced hybridization corresponds to higher interfacial stability. The valence 
band maxima (VBM) of the subunits were evaluated by referring the energies of the highest occupied bands to the electrostatic potential energy in the vacuum region. The calculated valence band edge for the $\mathrm{Pt}(111)$ and the Fe-terminated $\alpha-\mathrm{Fe}_{2} \mathrm{O}_{3}(0001)$ surfaces are at $5.55 \mathrm{eV}$ and $-4.13 \mathrm{eV}$. This finding would suggest a charge flow from Fe-terminated surface to $\mathrm{Pt}(111)$. According to the computed charge density difference plot (FIG. 8. a)), small charge depletion regions are indeed observed on the outmost Fe atom and also on the $\mathrm{O}$ atoms close to the interface. However, the charge accumulation mostly takes place between the substrate and the overlayer. On the contrary, the VBM of $\mathrm{O}_{3}$-terminated constrained clean surface is situated significantly lower $\left(\mathrm{E}_{\mathrm{VBM}}=-8.32 \mathrm{eV}\right)$ than the $\mathrm{VBM}$ of $\mathrm{Pt}(111)$ giving rise to a considerable charge transfer from the substrate to the overlayer. The computed VBM for the $\mathrm{Pt}(111)$ substrate and the $\mathrm{O}_{3}$-terminated overlayer are in line with previous theoretical investigation. ${ }^{39}$ The nature of the charge transfer is confirmed by the computed charge density difference plot for $\mathrm{O}_{3}$-terminated heterostructure (see FIG. 8. b)), thus a gain of electrons from the first layer of $\mathrm{Pt}$ atoms is observed on the oxygen atoms at the interface.

a)

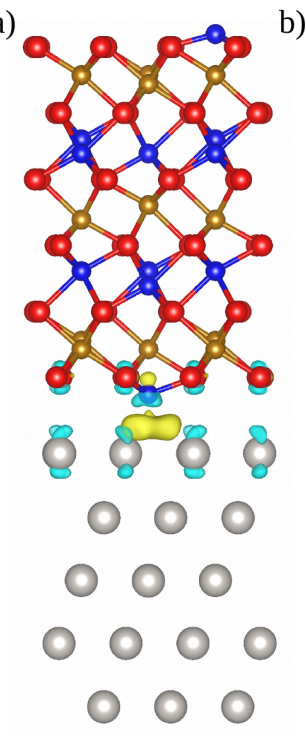

b)

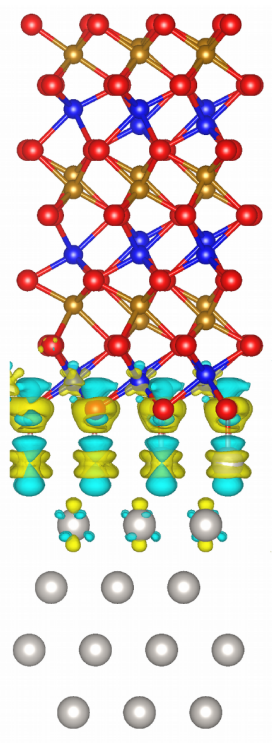

FIG. 8. Charge density differences of the most stable a) Fe (at hollow fcc site adsorption configuration)- and b) $\mathrm{O}_{3}$-terminated (at hollow hcp site adsorption configuration) $\mathrm{Pt} / \mathrm{Fe}_{2} \mathrm{O}_{3}$ heterostructures. Yellow and turquoise isosurfaces correspond to the accumulation and depletion of electronic densities. The isovalue is 0.006 . 


\section{CONCLUSIONS}

In summary, this work reports a complete investigation of the $\mathrm{Pt}(111) / \alpha-\mathrm{Fe}_{2} \mathrm{O}_{3}(0001)$ system, to determine the nature of this interface. Heterostructures have been considered for both Fe- and $\mathrm{O}_{3}$-terminated surfaces. To analyse the different determining factors, isolated hematite has been first considered, then the influence of the compressive strain induced by the mismatch with the substrate, and finally the electronic effect of $\operatorname{Pt}(111)$ on the constrained hematite.

While the Fe-terminated surface is more stable for isolated hematite, the $\mathrm{O}_{3}$-terminated one is less sensitive to the strain. Behaviors of both terminations also differ regarding their interaction with the $\mathrm{Pt}(111)$ substrate. Both terminations adsorbed preferably on the hollow sites. However the interaction of hematite with $\mathrm{Pt}(111)$ is much stronger with the $\mathrm{O}_{3}{ }^{-}$ terminated surface than with the Fe-terminated one. Finally as both strain and interaction energies are favorable towards $\mathrm{O}_{3}$ surface, this results in a large stability for $\mathrm{O}_{3}$-terminated heterostructures, while the Fe-terminated ones are unstable.

Thus, this work unravels the nature of $\mathrm{Pt}(111) / \alpha-\mathrm{Fe}_{2} \mathrm{O}_{3}(0001)$ interface: one can expect an epitaxial growth of $\mathrm{O}_{3}$-terminated heterostructures. This represents a first step towards a better understanding of $\mathrm{Pt} /$ hematite systems, which will be a crucial point for further studies.

\section{ACKNOWLEDGEMENT}

Calculations were performed using HPC resources from DNUM CCUB (Centre de Calcul de l'Université de Bourgogne). The authors also thanks the ANR for financial support through project ANR-15-CE05-PHOTO-POT. 


\section{REFERENCES}

${ }^{1}$ G. Wang, H. Wang, Y. Ling, Y. Tang, X. Yang, R. C. Fitzmorris, C. Wang, J. Z. Zhang, and Y. Li, Nano Lett. 11, 3026 (2011).

${ }^{2}$ G. Wang, Y. Yang, Y. Ling, H. Wang, X. Lu, Y.-C. Pu, J. Z. Zhang, Y. Tong, and Y. Li, J. Mater. Chem. A 4, 2849 (2016).

${ }^{3}$ S. Cao, X. Yan, Z. Kang, Q. Liang, X. Liao, and Y. Zhang, Nano Energy 24, 25 (2016).

${ }^{4}$ M. Li, Y. Yang, Y. Ling, W. Qiu, F. Wang, T. Liu, Y. Song, X. Liu, P. Fang, Y. Tong, and Y. Li, Nano Lett. 17, 2490 (2017).

${ }^{5}$ S. Kumar, K. Ojha, and A. K. Ganguli, Adv. Mater. Interfaces 4, 1600981 (2017).

${ }^{6}$ K. Sivula, F. Le Formal, and M. Grätzel, ChemSusChem 4, 432 (2011).

${ }^{7}$ S. D. Tilley, M. Cornuz, K. Sivula, and M. Grätzel, Angewandte Chemie 122, 6549 (2010).

${ }^{8}$ Y.-S. Hu, A. Kleiman-Shwarsctein, A. J. Forman, D. Hazen, J.-N. Park, and E. W. McFarland, Chem. Mater. 20, 3803 (2008).

${ }^{9}$ A. Kleiman-Shwarsctein, Y.-S. Hu, A. J. Forman, G. D. Stucky, and E. W. McFarland, J. Phys. Chem. C 112, 15900 (2008).

${ }^{10}$ H. Magnan, D. Stanescu, M. Rioult, E. Fonda, and A. Barbier, Applied Physics Letters 101, 133908 (2012).

${ }^{11}$ C. Miao, T. Shi, G. Xu, S. Ji, and C. Ye, ACS Appl. Mater. Interfaces 5, 1310 (2013).

${ }^{12}$ R. Zhang, L. Yang, X. Huang, T. Chen, F. Qu, Z. Liu, G. Du, A. M. Asiri, and X. Sun, J. Mater. Chem. A 5, 12086 (2017).

${ }^{13}$ O. Neufeld and M. C. Toroker, J. Phys. Chem. C 119, 5836 (2015).

${ }^{14}$ X. Yang, R. Liu, C. Du, P. Dai, Z. Zheng, and D. Wang, ACS Appl. Mater. Interfaces 6, 12005 (2014).

${ }^{15}$ C. X. Kronawitter, L. Vayssieres, S. Shen, L. Guo, D. A. Wheeler, J. Z. Zhang, B. R. Antoun, and S. S. Mao, Energy Environ. Sci. 4, 3889 (2011).

${ }^{16}$ O. Neufeld, N. Yatom, and M. C. Toroker, ACS Catalysis 5, 7237 (2015).

${ }^{17}$ Y. Lin, S. Zhou, S. W. Sheehan, and D. Wang, J. Am. Chem. Soc. 133, 2398 (2011).

${ }^{18}$ C. Y. Cummings, F. Marken, L. M. Peter, K. G. Upul Wijayantha, and A. A. Tahir, J. Am. Chem. Soc. 134, 1228 (2012).

${ }^{19}$ A. Barbier, A. Stierle, N. Kasper, M.-J. Guittet, and J. Jupille, Phys. Rev. B 75, 233406 (2007). 
${ }^{20}$ M. Lübbe and W. Moritz, J. Phys.: Condens. Matter 21, 134010 (2009).

${ }^{21}$ G. Ketteler, W. Weiss, and W. Ranke, Surf. Rev. Lett. 08, 661 (2001).

${ }^{22}$ F. Alvarez-Ramìrez, J. Martìnez-Magadàn, J. Gomes, and F. Illas, Surf. Sci. 558, 4 (2004).

${ }^{23}$ A. Rohrbach, J. Hafner, and G. Kresse, Phys. Rev. B 70, 125426 (2004).

${ }^{24}$ A. Kiejna and T. Pabisiak, J. Phys.: Condens. Matter 24, 095003 (2012).

${ }^{25}$ A. Kiejna and T. Pabisiak, J. Phys. Chem. C 117, 24339 (2013).

${ }^{26}$ X. Huang, S. K. Ramadugu, and S. E. Mason, J. Phys. Chem. C 120, 4919 (2016).

${ }^{27}$ T. P. Trainor, A. M. Chaka, P. J. Eng, M. Newville, G. A. Waychunas, J. G. Catalano, and G. E. Brown, Surf. Sci. 573, 204 (2004).

${ }^{28}$ S. Yin, X. Ma, and D. Ellis, Surf. Sci. 601, 2426 (2007).

${ }^{29}$ M.-T. Nguyen, N. Seriani, and R. Gebauer, J. Chem. Phys. 138, 194709 (2013).

${ }^{30}$ M.-T. Nguyen, N. Seriani, S. Piccinin, and R. Gebauer, J. Chem. Phys. 140, 064703 (2014).

${ }^{31}$ S. Yin and D. Ellis, Surf. Sci. 602, 2047 (2008).

${ }^{32}$ R. Ovcharenko, E. Voloshina, and J. Sauer, Phys. Chem. Chem. Phys. 18, 25560 (2016).

${ }^{33}$ P. Liao, J. A. Keith, and E. A. Carter, J. Am. Chem. Soc. 134, 13296 (2012).

${ }^{34}$ M. C. Toroker, J. Phys. Chem. C 118, 23162 (2014).

${ }^{35}$ N. Yatom, O. Neufeld, and M. C. Toroker, J. Phys. Chem. C 119, 24789 (2015).

${ }^{36}$ N. J. Mosey, P. Liao, and E. A. Carter, J. Chem. Phys. 129, 014103 (2008).

${ }^{37}$ A. Barbier, R. Belkhou, P. Ohresser, M. Gautier-Soyer, O. Bezencenet, M. Mulazzi, M.-J. Guittet, and J.-B. Moussy, Phys. Rev. B 72, 245423 (2005).

${ }^{38}$ E. Thimsen, F. Le Formal, M. Grätzel, and S. C. Warren, Nano Letters 11, 35 (2011).

${ }^{39}$ O. Neufeld and M. C. Toroker, Phys. Chem. Chem. Phys. 17, 24129 (2015).

${ }^{40}$ O. Neufeld, A. S. Reshef, L. Schein-Lubomirsky, and M. C. Toroker, J. Mater. Chem. C 4, 8989 (2016).

${ }^{41}$ S. Shaikhutdinov and W. Weiss, Surface Science 432, L627 (1999).

${ }^{42}$ X.-G. Wang, W. Weiss, S. K. Shaikhutdinov, M. Ritter, M. Petersen, F. Wagner, R. Schlögl, and M. Scheffler, Phys. Rev. Lett. 81, 1038 (1998).

${ }^{43}$ G. Kresse and J. Furthmüller, Comput. Mater. Sci. 6, 15 (1996).

${ }^{44}$ G. Kresse and J. Furthmüller, Phys. Rev. B 54, 11169 (1996).

${ }^{45}$ G. Kresse and D. Joubert, Phys. Rev. B 59, 1758 (1999). 
${ }^{46}$ J. P. Perdew, K. Burke, and M. Ernzerhof, Phys. Rev. Lett. 77, 3865 (1996).

${ }^{47}$ S. L. Dudarev, G. A. Botton, S. Y. Savrasov, C. J. Humphreys, and A. P. Sutton, Phys. Rev. B 57, 1505 (1998).

${ }^{48}$ P. E. Blöchl, O. Jepsen, and O. K. Andersen, Phys. Rev. B 49, 16223 (1994).

${ }^{49}$ G. Rollmann, A. Rohrbach, P. Entel, and J. Hafner, Phys. Rev. B 69, 165107 (2004).

${ }^{50}$ S. Liu, S. Wang, J. Guo, and Q. Guo, RSC Adv. 2, 9938 (2012).

${ }^{51}$ H. J. Kulik and N. Marzari, J. Chem. Phys. 135, 194105 (2011).

${ }^{52}$ H. J. Kulik and N. Marzari, J. Chem. Phys. 134, 094103 (2011).

${ }^{53}$ P. Liao and E. A. Carter, Phys. Chem. Chem. Phys. 13, 15189 (2011).

${ }^{54}$ E. Krén, P. Szabó, and G. Konczos, Phys. Lett. 19, 103 (1965).

${ }^{55}$ P. Merchant, R. Collins, R. Kershaw, K. Dwight, and A. Wold, Journal of Solid State Chemistry 27, 307 (1979). 